\title{
Identificación de Helicobacter pylori por medio de la coloración especial de Warthin-Starry en biopsias de pacientes con gastritis crónica folicular, previamente negativas en la tinción de hematoxilina-eosina
}

\author{
Warthin-Starry stain identification of Helicobacter pylori in biopsies of \\ patients who previously tested negative in hematoxylin-eosin staining for \\ follicular gastritis
}

Enoc Ahumada R., MD,,$^{*}$ Marcela Rodríguez G., MD, ${ }^{2}$ Estefanny Johanna Hidalgo P., MD, ${ }^{3}$ Juliana Ahumada D., MD, ${ }^{4}$ John Fredy Castro-Álvarez, MB, MSc, PhD. ${ }^{5}$

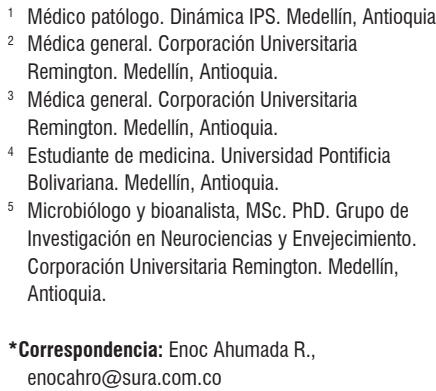

\section{Resumen}

Las técnicas empleadas para la detección del Helicobacter pylori (H. pylori) son no invasivas e invasivas. En estas últimas, la presencia del $H$. pylori se determina a partir de la tinción de hematoxilina-eosina (HE), prueba rutinaria, mientras que en pocas ocasiones se aplica la tinción de Warthin-Starry (WS) como coloración especial. Objetivo: identificar la presencia de H. pylori por medio de la coloración especial de la WS en biopsias de pacientes con gastritis crónica folicular, previamente negativas en la tinción HE. Materiales y métodos: se desarrolló un estudio de tipo descriptivo transversal, en un período de 12 meses. Se tomaron los bloques de parafina de las muestras de la mucosa gástrica de pacientes con diagnóstico de gastritis crónica e hiperplasia folicular. Además, se extrajo un corte histológico del mismo bloque, al cual se le aplicó HE y se determinó la presencia o ausencia de $H$. pylori. Así, de estar ausente, se tomó del mismo bloque un corte adicional y se aplicó WS. Esto se evaluó con el fin de identificar la existencia o no del bacilo. Resultados: se recolectaron 314 muestras; 209 fueron negativas y 105 fueron positivas para HE. El 45 \% (94) de estas muestras fueron positivas respecto a la presencia del bacilo, al aplicar la segunda coloración, y el $55 \%$ (115) de las muestras persistieron negativas. Conclusión: el hallazgo de $H$. pylori es significativamente alto al aplicar la coloración de WS a muestras cuyo estudio histológico evidenció la ausencia del bacilo en biopsias de la mucosa gástrica, especialmente en muestras con escasa cantidad de bacterias.

\section{Palabras claves}

Gastritis crónica, hiperplasia folicular, Helicobacter pylori, hematoxilina-eosina, Warthin-Starry.

\section{Abstract}

Non-invasive and invasive techniques can be used for detection of Helicobacter pylori. An invasive technique identifies the bacteria through routine hematoxylin-eosin staining. Warthin-Starry stain is rarely used. Objective: Our objective was to identify $H$. pylori by Warthin-Starry staining of patient's biopsies with chronic follicular gastritis who had previously tested negative in hematoxylin-eosin staining. Materials and methods: This is a descriptive, cross-sectional descriptive study that was carried out over a period of 12 months. The study examined paraffin blocks of samples taken from the gastric mucosa of patients diagnosed with chronic gastritis and follicular hyperplasia. A histological section was extracted from a block and tested with hematoxylin-eosin staining for the presence or absence of $H$. pylori. If absent, an additional cut was taken from the same block and Warthin-Starry staining was used to retest for the presence of the bacteria. Results: Of the 314 samples collected, 209 tested negative, and 105 tested positive for $H$. pylori when hematoxylin-eosin staining was used. Of the 209 negative samples, $45 \%$ (94) tested positive when Warthin Starry stain was used, and $55 \%$ (115) still tested negative. Conclusion: Findings of $H$. pylori are significantly higher when Warthin Starry stain was used to test samples whose previous histological study had evidenced an absence of the bacillus, especially in samples with a small amount of bacteria.

\section{Keywords}

Chronic gastritis, follicular hyperplasia, Helicobacter pylori, Hematoxylin-Eosin, Warthin Starry. 


\section{INTRODUCCIÓN}

La enfermedad ácido péptica constituye una de las principales causas de consulta médica en el ámbito colombiano; el $80 \%$ de estos casos se dan por gastritis (1), la cual se define como la inflamación de la mucosa gástrica, a causa de un desbalance entre los factores protectores y promotores de la inflamación (2). Se ha determinado un conjunto de factores de riesgo, dentro de los cuales se halla el Helicobacter pylori (H. pylori), que se considera uno de los más importantes, especialmente en la patogenia de la gastritis crónica con hiperplasia folicular (3).

Este tipo de gastritis produce una fuerte reacción inflamatoria, caracterizada por un denso infiltrado de células mononucleares, principalmente monocitos, y la formación de agregados o folículos linfoides con centro germinal (4). Estudios recientes sugieren que la inflamación persistente ocasionada por este tipo de gastritis puede incrementar el riesgo de desarrollar linfomas del tejido linfoide asociado a las mucosas (Mucosa-Associated Lymphoid Tissue, MALT) de bajo grado (un tipo de neoplasia gástrica) y adenocarcinoma (5).

Se prevé que cerca del $60 \%$ de la población mundial se encuentra infectada por el $H$. pylori, razón por la cual se convierte en la infección bacteriana crónica más común a nivel global (6). En Colombia, la prevalencia de la infección por $H$. pylori en los adultos es alta y se asocia a condiciones de insalubridad y estilos de vida poco saludables (7). Respecto a la vía de transmisión de la bacteria, el contacto persona a persona se considera la vía más implicada, ya sea, fecal-oral, oral-oral o gástrica-oral (8).

Asimismo, el método más empleado para el diagnóstico de este tipo de gastritis es el anatomopatológico, el cual consiste en la observación de la bacteria por medio de microscopia óptica, previo tratamiento del tejido que se va a observar. Este tratamiento incluye deshidratación con calor y aplicación de la tinción rutinaria de hematoxilinaeosina (HE). Las bacterias que están dentro del moco y en la superficie del epitelio pueden observarse con la tinción $\mathrm{HE}$, pero aquellas que se adhieren estrechamente a las células fagocitadas por neutrófilos generalmente son indistinguibles de las células adyacentes (9).

La HE tiene una alta sensibilidad para detectar la presencia de H. pylori en las biopsias de pacientes infectados. No obstante, factores como los pacientes con tratamiento previo; una escasa cantidad de H. pylori en la muestra, y condiciones técnicas como la calidad de la coloración y la experticia del observador, entre otros, conducen a la necesidad de utilizar tinciones auxiliares como la de Warthin-Starry (WS), la cual está indicada en gastritis crónica folicular (10).

La WS tiene la capacidad de resaltar las bacterias ocultas en el moco gástrico, debido al contraste de tonalidades (fondo amarillo parduzco), en comparación con la colora- ción de HE (morado-rosado); en la primera sobresalen los bacilos por el contraste, mientras que lo mismo no ocurre en la segunda (11).

El diagnóstico oportuno es importante para establecer un tratamiento precoz, sobre la base de combinaciones de regímenes triples de medicamentos tipo antimicrobianos, a fin de prevenir complicaciones futuras relacionadas con la persistencia del bacilo (12). Entre tanto, el propósito de este estudio es determinar la presencia de $H$. pylori a partir de la coloración especial de la WS en biopsias de pacientes con gastritis crónica folicular, previamente negativas en la tinción de HE.

\section{MATERIALES Y MÉTODOS}

Se realizó un estudio de tipo descriptivo transversal que se efectuó entre agosto de 2016 y julio de 2017. Para tal propósito, se aplicó un muestreo por conveniencia, en el cual se analizaron las muestras que llegaron al laboratorio y que cumplían con los siguientes criterios de inclusión: hombres y mujeres de Medellín que consultaron a un centro de referencia de la ciudad, con diagnóstico de gastritis crónica e hiperplasia folicular y ausencia de H. pylori en la biopsia gástrica, mediante la coloración rutinaria HE. Se consideraron muestras anatomopatológicas recolectadas y almacenadas de forma incorrecta como criterio de exclusión.

En el laboratorio de patología de Dinámica IPS (sede Medellín), se tomaron bloques de parafina de muestras de la mucosa gástrica, obtenidos de pacientes por vía endoscópica. Al corte histológico extraído de cada bloque se le aplicó la coloración rutinaria de HE y se siguieron las instrucciones, de acuerdo con el protocolo del laboratorio de las Fuerzas Armadas de Estados Unidos. Para ello se usaron reactivos HE, comercialmente disponibles (Instant Hematoxylin de Thermo scientific ${ }^{\oplus}$ ).

Luego de la tinción con HE, se observó la muestra por medio de microscopia óptica y se determinó la presencia o la ausencia de H. pylori; en caso de estar ausente, se tomó del mismo bloque un corte adicional, el cual se sometió a la tinción especial de WS, preparada en el laboratorio según el protocolo de las Fuerzas Armadas de Estados Unidos (11).

Se siguieron los pasos descritos a continuación: i) se desparafinó el tejido, ii) se prepararon dos baños de flotación, uno de $43^{\circ} \mathrm{C}$ de impregnación y otro de $54^{\circ} \mathrm{C}$ de revelación, para luego tomar la temperatura, iii) en el baño de impregnación, se adicionó nitrato de plata al $1 \%$ y cuando estuvo caliente se instalaron las placas por $30 \mathrm{~min}$, iv) en el baño de revelación, se puso el nitrato de plata durante 30 minutos, así como gelatina al $5 \%$, hidroquinona o pirocatecol al 0,15\% y agua destilada, v) pasados $30 \mathrm{~min}$, se tomaron $1,5 \mathrm{~mL}$ de nitrato de plata al $2 \% ; 3,75 \mathrm{~mL}$ de gelatina y $2 \mathrm{~mL}$ de pirocatecol, y se mezclaron, vi) posterior a 
ello, se extrajeron las placas del baño de impregnación de nitrato de plata al $1 \%$, se ubicaron en la rejilla y se aplicó la solución anterior hasta obtener un color amarillo o café dorado, vii) se lavó con agua tridestilada caliente y se deshidrató con calor, viii) se evaluó a partir de la observación por microscopia óptica, igual que el corte anterior, con el fin de identificar la existencia o no del bacilo.

Solo en los casos de pacientes negativos para HE se registraron datos del reporte de patología, de los cuales se extrajeron las variables correspondientes para los análisis. Con los resultados obtenidos, se construyó una base de datos en Microsoft Excel y se analizaron variables como la presencia de H. pylori por WS, la cantidad de H. pylori por WS, la existencia de inflamación, el grado de dicha inflamación, la actividad inflamatoria, hiperplasia y características demográficas adicionales como la edad y el género, obtenidas de los registros clínicos cuando el paciente ingresó.

Asimismo, en el análisis estadístico se consideraron medidas descriptivas como la frecuencia relativa y la absoluta, así como medidas de tendencia central y de dispersión. Estas fueron analizadas con el software IBM SPSS statistics para Windows versión 24.0.

\section{RESULTADOS}

Se analizó un total de 314 muestras, de las cuales 105 fueron positivas y 209 fueron negativas para H. pylori, en la tin- ción de HE. Durante el estudio se incluyeron solo las muestras negativas por $\mathrm{HE}$ y se excluyeron aquellas que fueron positivas. De las 209 muestras negativas por HE, el $45 \%$ (94) fueron positivas respecto a la presencia de la bacteria al realizar la segunda coloración de WS, y el $55 \%$ (115) de las muestras persistieron negativas (Figura 1).

La coloración especial de WS detectó, en su totalidad, cantidades escasas del bacilo en las biopsias que previamente habían sido negativas para HE (Figura 2). De las 209 muestras del estudio, el 66,9 \% (140) correspondieron a pacientes del género femenino y el $33 \%$ (69) de ellas al género masculino (33\%). Entre tanto, de las 140 muestras de pacientes del género femenino, 62 fueron positivas y 78 negativas por WS, mientras que de las 69 muestras del género masculino, 32 fueron positivas y 37 fueron negativas por WS.

El promedio de edad para las mujeres con gastritis crónica folicular en presencia de $H$. pylori fue de 50 años, mientras que en hombres fue de 42. En las 209 muestras negativas para $\mathrm{HE}$, el rango de edad de los pacientes atendidos osciló entre 1 y 90 años. Entre tanto, se observó que el grupo etario más frecuentemente afectado estuvo entre los 41-60 años, pues 46 pacientes fueron positivos para H. pylori y 47 negativos para la WS.

Por otra parte, la población menos afectada estuvo entre los 81-100 años y se presentó solo un caso positivo para H. pylori al aplicarse la WS. Así pues, se encontró una

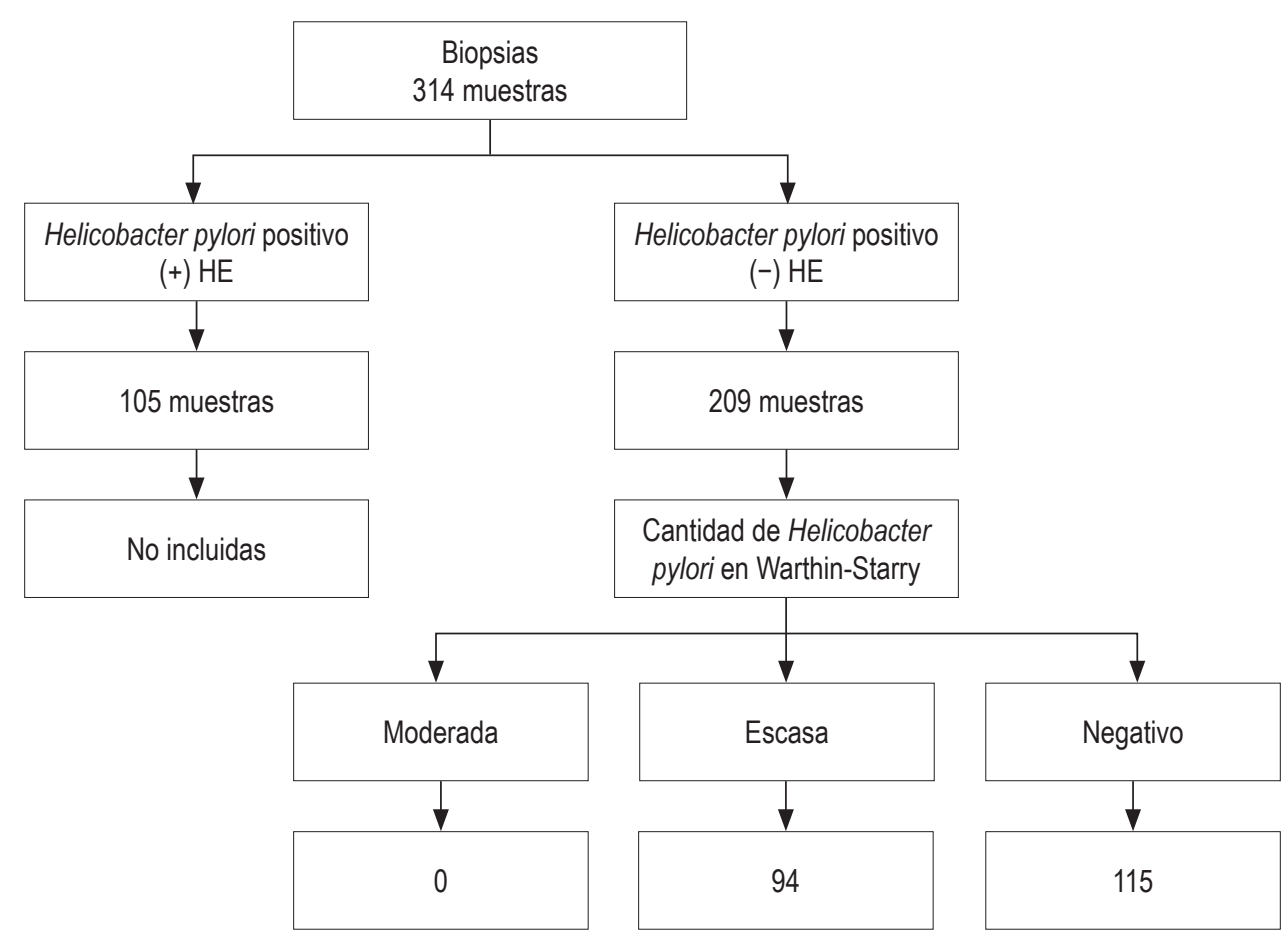

Figura 1. Distribución de las muestras analizadas por HE y WS. De las 314 muestras de la mucosa gastrica, 105 fueron positivas y 209 negativas al aplicar la coloración de HE. HE: hematoxilina-eosina. 


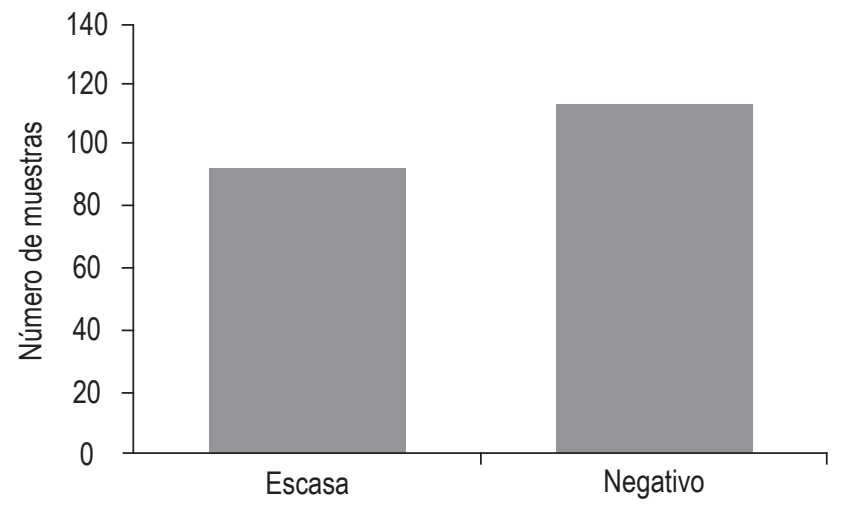

Figura 2. Cantidad de H. pylori en la coloración de WS. La coloración especial de WS detectó, en su mayoría, cantidades escasas del bacilo en las biopsias previamente negativas para HE. WS: tinción de Warthin-Starry

diferencia marcada en el grupo de 0-20 años, con una frecuencia de casos de 8 positivos y 21 negativos para la WS (Figura 3).

Con relación a la cantidad de bacterias, se encontró que el $100 \%$ (94) de aquellos pacientes que resultaron positivos por WS presentaron una escasa cantidad de $H$. pylori. También se detectó que, de las 94 muestras positivas para WS, el $84 \%$ (79) presentaron un grado de inflamación moderado en comparación con 91 muestras negativas; un 9,6 \% (9) mostraron un grado de inflamación severa (14 en las negativas), y un $6,4 \%(6)$, un grado de inflamación leve (10 en las negativas) (Figura 4).
Con respecto a la actividad inflamatoria, se identificó que el $91 \%$ (84) de las muestras positivas por WS presentaron una actividad inflamatoria leve, en comparación con 107 muestras negativas (Figura 5).

$\mathrm{Al}$ comparar las dos tinciones, se puede observar que en HE se presentan agregados linfoides con centros germinales, pero no se logra identificar claramente el $H$. pylori (Figura 6A), a diferencia de la tinción con WS, en la cual se destacan escasos bacilos que corresponden a bacilos de H. pylori (Figura 6B).

\section{DISCUSIÓN}

En el presente estudio, se compararon dos métodos de tinciones histológicas, con el objetivo de determinar el valor diagnóstico de la tinción WS para la identificación de $H$. pylori en biopsias gástricas de pacientes con gastritis crónica folicular, previamente negativas con la coloración de HE.

La WS es una coloración especial empleada para la detección histológica de $H$. pylori y de espiroquetas en muestras de tejido gástrico (13). Su componente principal es el nitrato de plata, el cual se precipita sobre la membrana del microorganismo y permite que esta se visualice más gruesa y sea fácil de identificar con el microscopio (14). La WS debe ser realizada por una persona experta en el campo de tinciones, debido a que demanda mucho cuidado, pues puede presentarse una precipitación excesiva de la plata o una decoloración excesiva de las muestras, lo que altera el resultado de la lectura del microscopio (15).

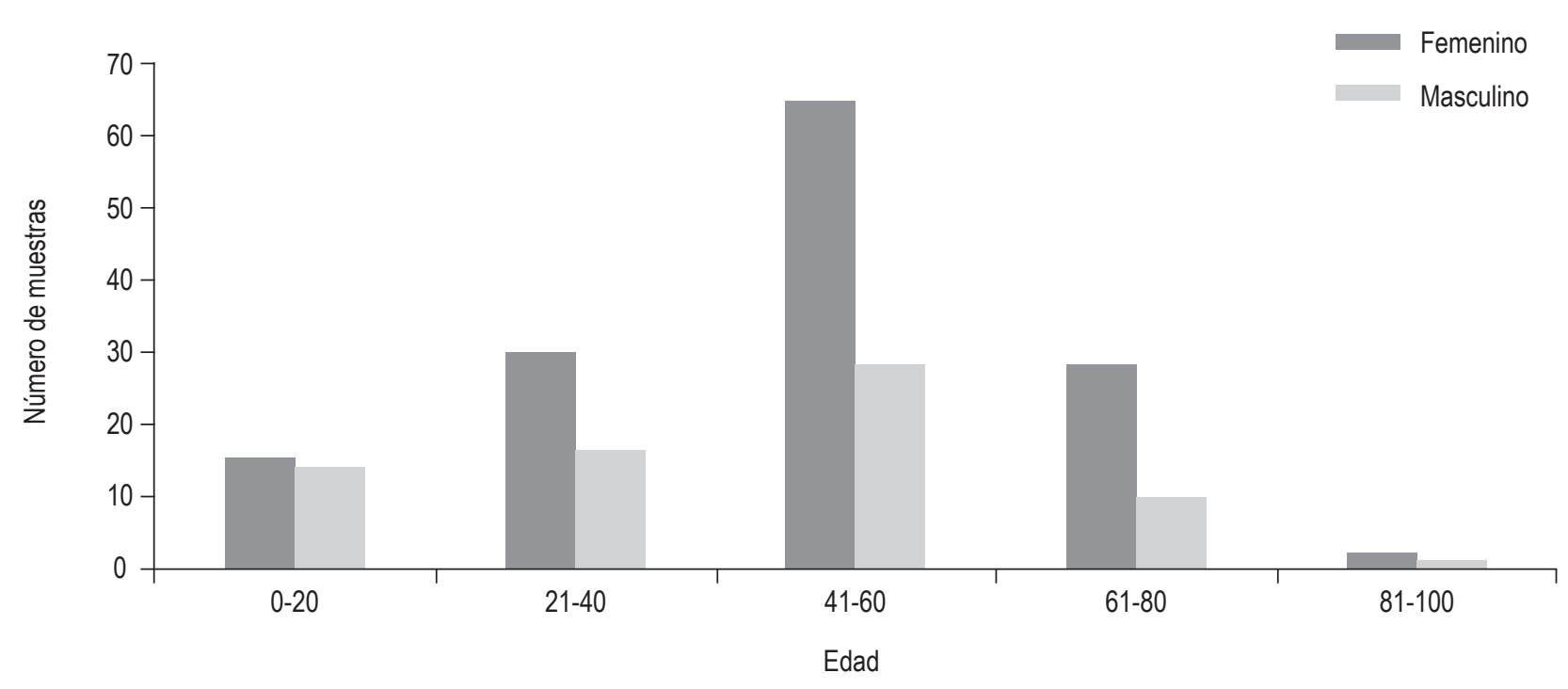

Figura 3. Grupo etario más afectado según la edad y el sexo. El promedio de edad para las mujeres con gastritis crónica folicular en presencia de $H$. pylori fue de 50 años, mientras que en hombres fue de 42 . El grupo etario más frecuentemente afectado estuvo entre los 41-60 años. 


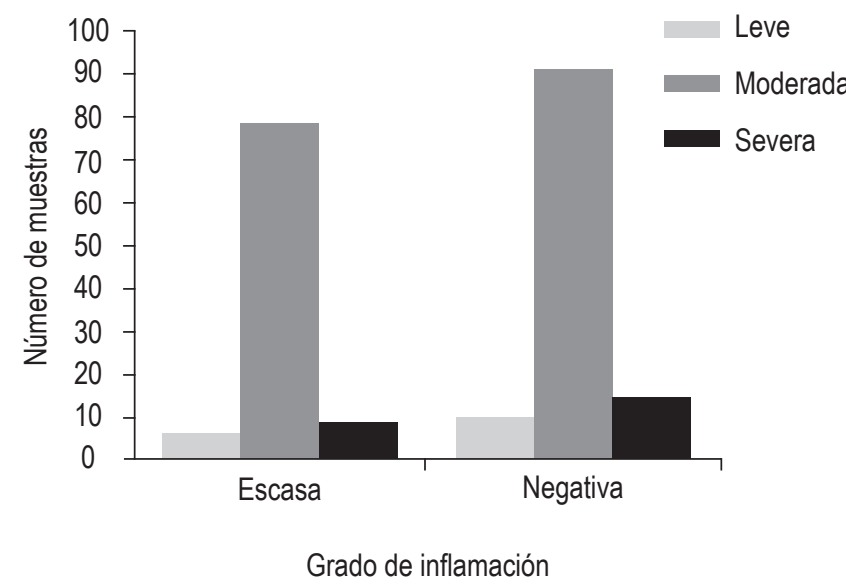

Figura 4. Relación del grado de inflamación con la cantidad de H. pylori presente en la coloración de la WS. Del total de las 94 muestras que fueron positivas para WS, el $84 \%$ (79) presentaron un grado de inflamación moderado, un 9,6 \% (9) mostró un grado de inflamación severa y un 6,4\% (6) un grado de inflamación leve.

En presencia de actividad inflamatoria leve, la tinción de WS se adhiere mejor a los bacilos, mientras que en la actividad inflamatoria moderada los infiltrados de células inflamatorias se superponen al bacilo y disminuyen la capacidad de fijación de WS a este bacilo, lo cual es relevante para el diagnóstico histológico, ya que, como lo estamos reportando en este estudio, la mayoría de las muestras presentan actividad inflamatoria leve.
Por esta razón, la aplicación de WS es ideal para detectar la presencia del bacilo. Similar a lo reportado por Velásquez y colaboradores (15), nuestro estudio encontró que la WS tiene la capacidad de identificar cantidades escasas de la bacteria, mientras que la $\mathrm{HE}$ tiene el potencial de teñir la bacteria cuando esta se encuentra en gran cantidad en los cortes histológicos, motivo por el cual la tinción de rutina HE genera falsos negativos (16).

Los resultados derivados del presente estudio confirman que la tinción especial de WS detecta con mayor frecuencia la presencia de H. pylori en los casos de gastritis crónica folicular previamente negativas con la coloración de HE, como se ha documentado en otros estudios (13-17).

Asimismo, el presente estudio concluye que la WS es más eficiente que la HE para confirmar la presencia de la bacteria en gastritis de patrón folicular, por lo cual se podría considerar aplicarla dentro de los protocolos diagnósticos en los laboratorios de patología locales como tinción inicial, debido a que esta práctica no es empleada por la mayoría de patólogos, al no evidenciar inicialmente el bacilo, el cual se expone al usar la WS.

Aunque la WS representa un mayor valor económico en su implementación en el laboratorio, un personal técnico especializado (18) y una mayor laboriosidad en la preparación de los reactivos -los cuales no están disponibles comercialmente en nuestro medio- haría más costo-efectivo el diagnóstico de H. pylori. A partir de ello, se propende por un diagnóstico y un tratamiento precoces, a fin de evitar las secuelas de esta bacteria, principalmente el cáncer gástrico.

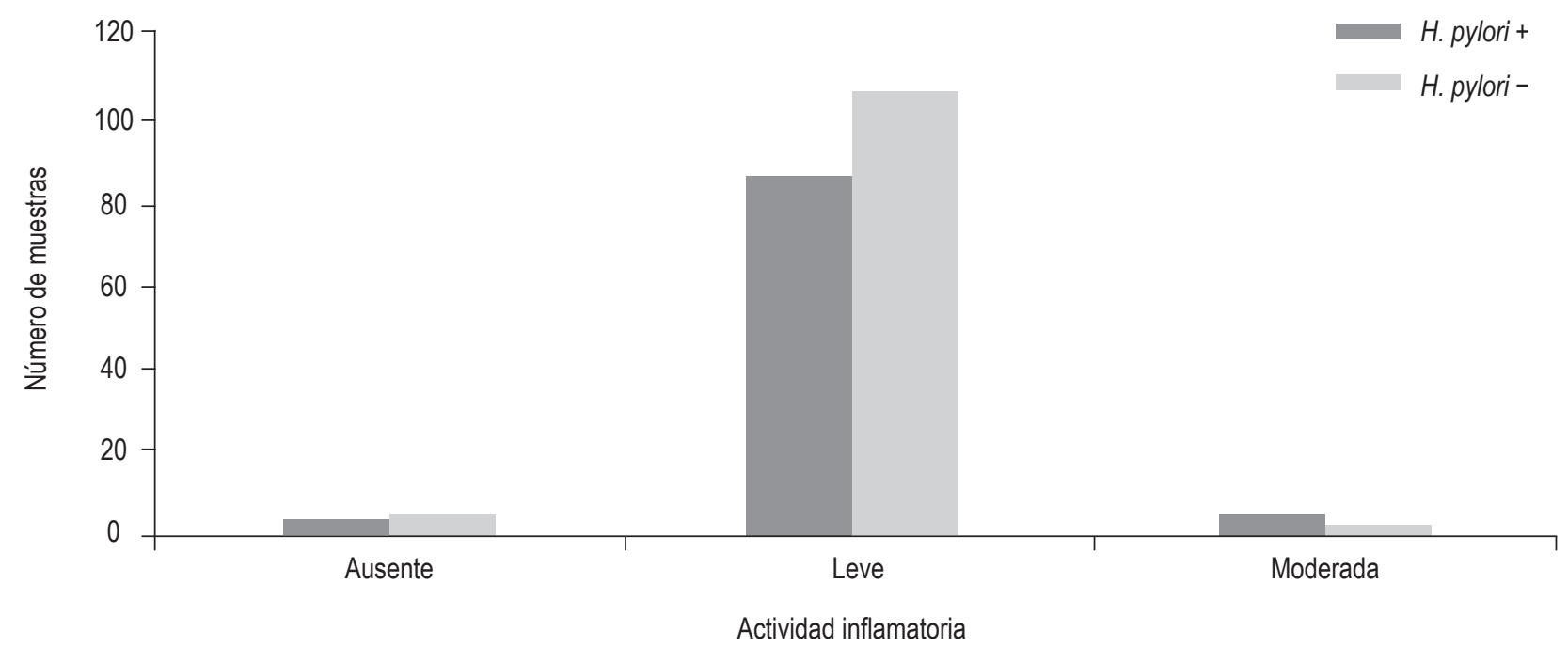

Figura 5. Presencia de H. pylori en la coloración de la WS de acuerdo con la actividad inflamatoria. Se identificó que el 91 \% (84) de las muestras positivas por WS presentaron una actividad inflamatoria leve, en comparación con 107 muestras negativas. 

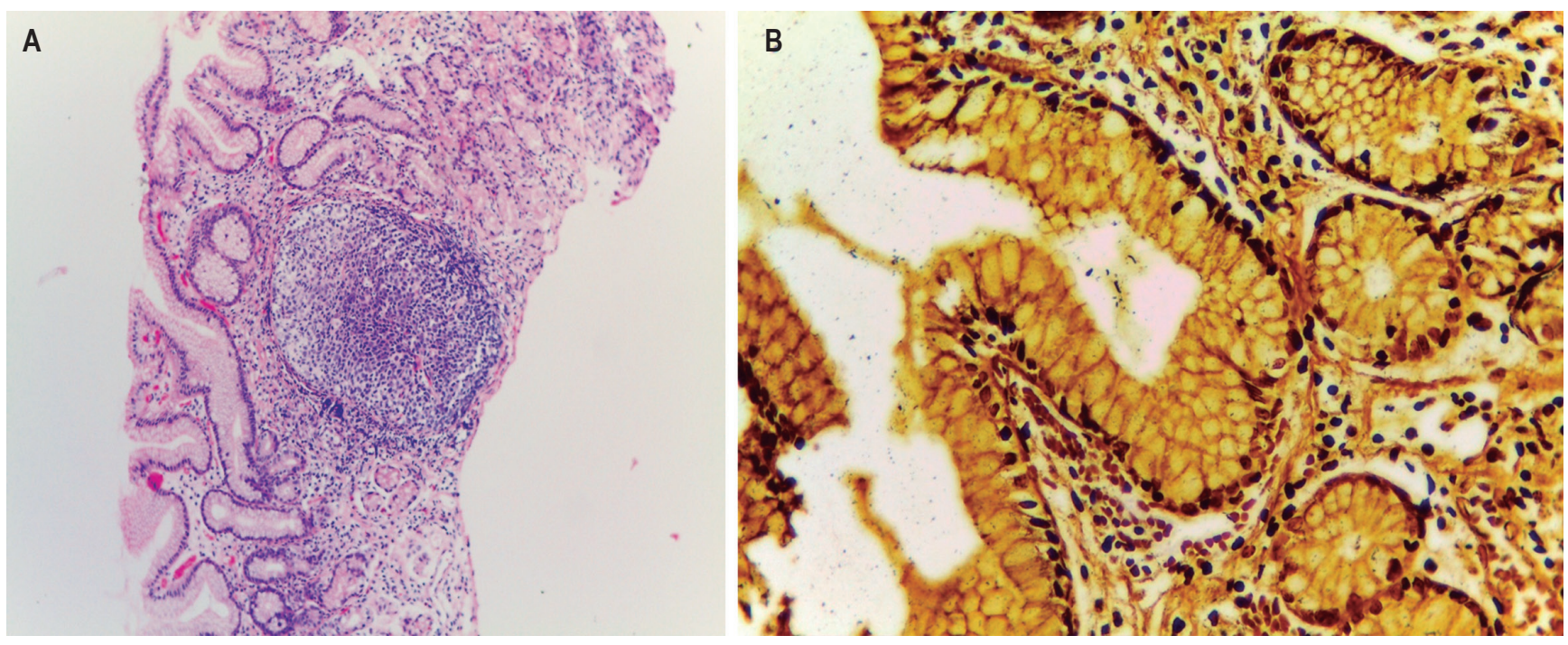

Figura 6. A. H. pylori en la coloración rutinaria de HE 4x, Se observan agregados linfoides con centros germinales activos. Los agregados están rodeados por un proceso inflamatorio linfoplasmocitario. B. H. pylori en la coloración especial de WS 40x. Se observa en la luz de algunas glándulas que se destacan escasos bacilos espirales negros, los cuales corresponden a bacilos $H$. pylori.

\section{Derecho a la privacidad y consentimiento informado}

Los autores declaran que en este artículo no aparecen datos personales de los pacientes.

\section{Conflictos de interés}

Los autores declaran que el proyecto no tiene conflictos de interés.

\section{REFERENCIAS}

1. Correa S, Cardona AF, Correa T, Correa LA, García HI, Estrada S. Prevalencia de Helicobacter pylori y características histopatológicas en biopsias gástricas de pacientes con síntomas dispépticos en un centro de referencia de Medellín. Rev Col Gastroenterol. 2016;31(1):9-15. https://doi. org/10.22516/25007440.67

2. Buriticá VJ, Becerra LF, Salazar A. Enfermedad ácido péptica. Arch Med Univ Manizales Fac Med. 2005;11:46-55. https://doi.org/10.30554/archmed.11.0.1534.2005

3. Makola D, Peura DA, Crowe SE. Helicobacter pylori infection and related gastrointestinal diseases. J Clin Gastroenterol. 2007;41(6):548-58. http://dx.doi. org/10.1097/MCG.0b013e318030e3c3

4. Garg B, Sandhu V, Sood N, Sood A, Malhotra V. Histopathological analysis of chronic gastritis and correlation of pathological features with each other and with endoscopic findings. Pol J Pathol. 2012;63(3):172-8. https://doi. org/10.5114/pjp.2012.31501
5. Ramírez A, Sánchez R. Helicobacter Pylori y Cáncer Gástrico. Rev Gastroenterol Perú. 2008;28:258-266.

6. Martínez JD, Riveros SC. Hiperplasia linfoide folicular gástrica e infección por Helicobacter pylori en adultos colombianos. 2009;24(2):148-156.

7. Camargo MC, Yepez MC, Cerón C, Guerrero N, Bravo LE, Correa P, et al. Age at acquisition of Helicobacter pylori infection: comparison of two areas with contrasting risk of gastric cancer. Helicobacter. 2004;9(3):262-70. https://doi. org/10.1111/j.1083-4389.2004.00221.x

8. Alba RS, Toledo RA, Viana ML. Helicobacter pylori: Clínica, diagnóstico y tratamiento. Rev Posgrado VIa Cátedra Med. 2006; 158:9-12.

9. Marín R, Salas P, Mena F, Sierra R. Identificación histológica de Helicobacter pylori por los métodos de tinción de Warthins-Stary y Giménez en biopsias gástricas. Rev Med Costa Rica Centroam. 1996;53(537):147-151.

10. Fallone CA, Loo VG, Lough J, Barkun AN. Hematoxylin and eosin staining of gastric tissue for the detection of Helicobacter pylori. Helicobacter. 1997;2(1):32-5. https:// doi.org/10.1111/j.1523-5378.1997.tb00054.x

11. Prophet EB, Mills B, Arrington J, Sobón L. Métodos histotecnológicos. Washington: Registro de Patología de los Estados Unidos de América (ARP) e Instituto de Patología de las Fuerzas Armadas de los Estados Unidos de América (AFIP);1995.

12. Campuzano G. Helicobacter Pylori: de la gastritis al cáncer gástrico. Medellín: Editora Médica Colombiana S.A., 8a edición; 2017. 
13. Kit de plateado según Warthin-Starry modificado para la detección de Helicobacter pylori y Spirochaetes en cortes parafínicos. Burlington: EMD Millipore Corporation; 2019.

14. Giugni MC, Benmelej A, Graciani G, Gómez JM, Roldán JN, Costamagna A, et al. Comparación de coloraciones histológicas para el diagnóstico de Helicobacter Pylori. Rev FABICIB. 1998;2(1):151-155. https://doi.org/10.14409/ fabicib.v2i1.611

15. Joachín ID, Mendoza AG, Salazar JL. Valor diagnóstico de la tinción de Warthin Starry para la identificación de H. pylori en biopsias gástricas. Guatemala: Universidad de San Carlos de Guatemala, Facultad de Ciencias Químicas y Farmacia; 2016.

16. Amores J, Arredondo A, Martínez B, Estrada Y, Pereira L, Potente A. Correlación histologicamicrobiológica en el diagnóstico de Helicobacter pylori. Rev Mex Patol Clin. 2010;57(3):135-142.

17. Ortiz-Martínez MA, Salazar-Valdez OR, Brito-Zurita OR, Abundis-Castro L, García-Bajeca C, Gutiérrez-López SJ, et al. Detección de Helicobacter pylori en niños con los métodos de Gram, Giemsa y Warthing-Starry, inicialmente negativos con otras técnicas histológicas. Rev Gastroenterol Mex. 2005;70(2):143-145.

18. Vela-Velásquez CT. Comparación entre las biopsias gástricas sin fijar 24 horas frente a la biopsia convencional para el diagnóstico de Helicobacter pylori en un hospital de referencia de Perú. Rev Perú Med Exp Salud Pública. 2011;28(1):42-46. https://doi.org/10.17843/rpmesp.2011.281.454 